\title{
PRINCIPAIS MÉTODOS DE DETECÇÃO DE MASTITES CLÍNICAS E SUBCLÍNICAS DE BOVINOS
}

\author{
Rafaela Rosa Maiochi ${ }^{1}$, Raquel Granato Alves Rodrigues ${ }^{2}$, Sheila Rezler Wosiacki ${ }^{3}$ \\ ${ }^{1}$ Médica Veterinária, Mestranda do Programa de Pós-graduação em Produção \\ Sustentável e Saúde Animal da Universidade Estadual de Maringá, Campus \\ Umuarama - Pr, Brasil, rafaelarmaiochi@gmail.com \\ ${ }^{2}$ Médica Veterinária, Mestranda do Programa de Pós-graduação em Produção \\ Sustentável e Saúde Animal da Universidade Estadual de Maringá, Campus \\ Umuarama - Pr, Brasil \\ ${ }^{3}$ Professora Doutora associada do Departamento de Medicina Veterinária da \\ Universidade Estadual de Maringá, Campus Umuarama - Pr, Brasil
}

Recebido em: 06/04/2019 - Aprovado em: 10/06/2019 - Publicado em: 30/06/2019 DOI: 10.18677/EnciBio_2019A104

\begin{abstract}
RESUMO
A mastite bovina, caracterizada pela inflamação da glândula mamária, é uma das doenças mais importantes e onerosas do gado leiteiro, podendo apresentar-se, de acordo com os sinais clínicos, como a forma clínica ou subclínica da enfermidade. É frequentemente observada no rebanho, gerando prejuízos econômicos diretos e indiretos, como a queda na produção de leite, o comprometimento da sanidade do animal acometido, os gastos com medicamentos, descarte precoce de animais que apresentem casos crônicos e a diminuição na qualidade do produto, devido à elevação da quantidade de células somáticas, à presença de patógenos e às alterações macroscópicas visualizadas no leite. A inserção e a permanência de métodos de diagnóstico na rotina do plantel, para ambas as formas da doença, é, ainda, uma das ferramentas mais eficazes para o controle da mastite e consequente qualidade do leite produzido.
\end{abstract}

PALAVRAS-CHAVE: diagnóstico; glândula mamária; mastite bovina.

\section{MAIN METHODS OF DETECTION OF CLINICAL AND SUBCLINICAL MASTITIS OF CATTLE: A REVIEW ABSTRACT}

Bovine mastitis, characterized by inflammation of the mammary gland, is one of the most important and onerous diseases of dairy cattle, can be presented, according to clinical signs, as the clinical or subclinical form of the disease. It is frequently observed in the herd, generating direct and indirect economic losses, such as the decrease in milk production, the compromised sanity of the affected animal, the expenses with medicines, the early culling of animals that present chronic cases and the decrease in product quality, due to the increase in the number of somatic cells, the presence of pathogens and the macroscopic alterations in the milk. The insertion and permanence of diagnostic methods in the routine of the establishment, for both forms of the disease, is still one of the most effective tools for the control of mastitis 
and consequent quality of the milk produced.

KEYWORDS: diagnosis; mammary gland; bovine mastitis.

\section{INTRODUÇÃO}

A mastite é um processo inflamatório da glândula mamária. Trata-se de uma resposta do tecido glandular do úbere a agressões físicas, reações alérgicas, metabólicas, fisiológicas ou presença de agentes infecciosos, que podem atingir esse local por diferentes vias (BELOTI et al., 2015). Segundo Langoni et al. (2013), uma vez que um microrganismo tenha se instalado na glândula mamária, ele se nutre dos componentes do leite e se multiplica, atingindo números muito elevados. É uma enfermidade multifatorial, de múltipla etiologia, incluindo micro-organismos como bactérias, vírus, fungos, leveduras e algas (LOPES et al., 2018).

A mastite continua sendo um dos principais problemas sanitários nos animais destinados à produção de leite, com alta prevalência, as infecções da glândula mamária impactam em grandes prejuízos econômicos na indústria leiteira (FITZPATRICK et al., 2013). De múltipla etiologia e de ocorrência mundial, sua frequência está relacionada com o manejo sanitário dos animais e da ordenha. Segundo Langoni et al. (2017), especificamente na mastite bovina pode-se afirmar, que se trata de um entrave para a pecuária leiteira, repercutindo negativamente no que se refere a qualidade do leite e problemas de saúde pública, tornando o produto final inadequado ao consumo e reduzindo o rendimento dos derivados lácteos na indústria de laticínios, além de diminuírem o tempo de prateleira destes (LANGONI, 2013). Ainda, os efeitos negativos da infecção afetam a saúde e o desempenho das vacas, podendo levar a grandes perdas de produtividade, à diminuição do desempenho reprodutivo, ao comprometimento da saúde e ao aumento do descarte de animais.

De acordo com Herbet et al. (2016), apesar da posição de destaque no cenário internacional de produção leiteira, o Brasil ainda apresenta baixa qualidade, principalmente microbiológica, devido à grande presença da mastite nos rebanhos brasileiros. Um grande desafio para produtores de leite é o controle desta enfermidade. Muitas vezes, a ausência do diagnóstico precoce é um fator limitante e decisivo para o sucesso do tratamento (LEÃO et al., 2015). Para o controle, medidas profiláticas de higiene são muito importantes. Várias medidas praticadas conjuntamente devem ser estabelecidas buscando-se a obtenção de produto de melhor qualidade, além de aumentar a produtividade do rebanho, a fim de atender um mercado consumidor mais informado e exigente. (CALLEFE; LANGONI, 2015).

O diagnóstico precoce da mastite permite minimizar perdas e estabelecer o protocolo de tratamento de forma econômica e eficiente, com maior índice de recuperação. De acordo com Paes et al. (2017), uma das ferramentas que contribui para o gerenciamento da pecuária leiteira do país atualmente é a adoção do controle leiteiro nas propriedades rurais.

Ressalta-se que a mastite bovina é, ainda, a doença que mais traz prejuízos econômicos ao produtor de leite atualmente, sendo de suma importância a utilização, na rotina da propriedade, de métodos que sejam capazes de identificar o início de uma contaminação ou confirmar a existência de uma infecção já instalada no animal. Perante o exposto, objetivou-se com essa revisão bibliográfica compilar os métodos utilizados para a detecção de mastites clínicas e subclínicas disponíveis. 


\section{Classificação das mastites quanto aos sinais clínicos}

Segundo Santos e Fonseca (2007), existem dois tipos de mastite que se dividem em dois grandes grupos, segundo a sua forma de manifestação: mastite clínica e mastite subclínica. No primeiro caso é possível observar alterações da glândula mamária, bem como alteração nas características do leite. A mastite clínica ocasiona perdas elevadas pelo descarte do leite, gastos com medicamentos, perda funcional de glândulas e até por morte do animal (LANGONI et al., 2016). Na mastite subclínica não há aparecimento de sinais evidentes, nem nas mamas, nem no aspecto do leite, não sendo possível a visualização de mudanças do úbere ou do leite (BRITO, 2007).

De acordo com Langoni et al. (2017), o impacto que a mastite causa sobre a qualidade do leite é reconhecido mundialmente e os programas para o seu controle devem ser entendidos como pilares de sustentação dos programas nacionais de qualidade do leite que devem ser pautados em medidas preventivas e na identificação e tratamento adequados dos animais infectados, sendo este um fator limitante e que apresenta maior dificuldade para ser atingido, devido a complexidade da etiologia das mastites, ao momento em que se diagnostica cada caso e aos aspectos de resistência microbiana (BARKEMA et al., 2006).

O diagnóstico da mastite clínica é realizado pela avaliação do exame físico do animal e sua glândula mamária e por meio da detecção de alterações macroscópicas no leite (SANTOS; FONSECA, 2007). Enquanto, Costa (2005) traz exames baseados no conteúdo celular do leite, como California Mastitis Test (CMT), Wisconsin Mastitis Test (WMT), Contagem de Células Somáticas (CCS), Whiteside, condutibilidade elétrica (CE), entre outros, como sendo métodos diagnósticos para a mastite subclínica.

\section{Detecção de mastites clínicas}

Segundo Stagnaferro et al. (2016), para detectar vacas com mastite clínica, os programas de monitoramento de saúde incluem a avaliação das características do leite, sinais de inflamação do úbere e sistêmicos da doença. A primeira etapa de monitoramento de casos de mastite clínica é a verificação de sinais clínicos por meio de exames físicos (BELOTI et al., 2015).

O diagnóstico precoce e o início do tratamento adequado dos casos de mastite clínica são fundamentais para se atingir os objetivos de um programa de controle (LANGONI et al, 2017).

\section{- Exame físico do animal}

O exame físico consiste na avaliação dos parâmetros do animal por meio da palpação e inspeção visual da glândula mamária, podendo ser realizada durante a ordenha, a depender dos sinais observados, um exame clínico completo no animal deve ser realizado, a fim de se identificar sinais de infecções sistêmicas (SANTOS; FONSECA, 2007; BELOTI et al., 2015).

Os sinais clínicos indicativos de mastite clínica podem ser sensibilidade ao toque, hiperemia, aumento da temperatura, edema, alteração da consistência do tecido mamário ou presença de nódulos, sendo sugestivo de formação de tecido conjuntivo cicatricial fibroso (BRITO, 2007; LANGONI, 2013). Sinais sistêmicos de inflamação podem incluir aumento da temperatura retal, alterações comportamentais, anorexia e apatia (NETO; ZAPPA, 2011). 
Seguindo Nero e Moreira (2015), o melhor momento para a verificação de alterações fisiológicas no úbere é após a ordenha, quando todo o quarto foi esvaziado e apresenta o seu aspecto normal.

\section{- Exame das características físicas do leite}

O principal método aplicado para o exame das características físicas do leite é o teste da caneca do fundo escuro. Segundo Santos e Fonseca (2007), esse teste deve ser realizado imediatamente antes de todas ordenhas e consiste na retirada dos 4 primeiros jatos de leite em superfície escura e telada com a finalidade de observar a consistência e alterações no leite, tais como presença de grumos ou coágulos, pus, sangue, leite aquoso ou qualquer outra alteração nas características do leite (figura 1). Como ocorre independência entre os quartos, esse teste deve ser realizado individualmente para cada porção do úbere (BRITO, 2002; BELOTI et al., 2015).

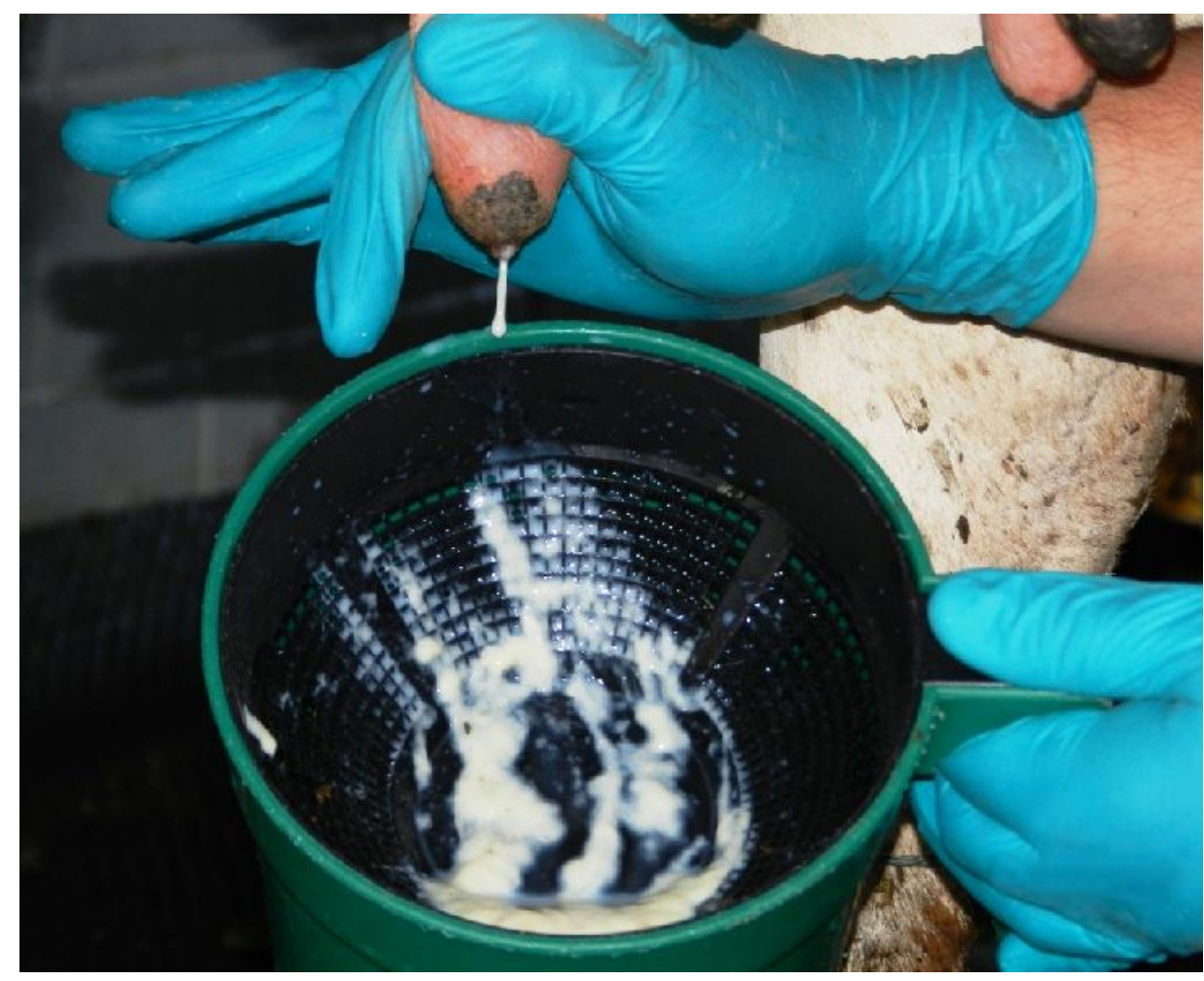

FIGURA 1 - Teste da caneca do fundo escuro indicando mastite clínica. Fonte: CHAPAVAL,(2016).

De acordo com Santos e Fonseca (2007), quando realizada precedendo a ordenha, a prática deste teste leva ao benefício do estímulo para a ejeção do leite e também permite a eliminação de grande parte dos microrganismos contaminantes do úbere que estão presentes nos primeiros jatos de leite (BELOTI et al., 2015).

\section{Detecção de mastites subclínicas}

Segundo Costa (2005), pode-se diagnosticar a mastite subclínica por meio de exames baseados no conteúdo celular do leite. Durante o processo infeccioso subclínico ocorrem alterações relacionadas ao aumento no número de células somáticas, imunoglobulinas, lipases e dos teores dos íons de cloro e sódio, além da diminuição nos teores de caseína, lactose, potássio, cálcio e gordura do leite (SANTOS; FONSECA, 2007). 
De acordo com Acosta et al. (2016), o aumento na contagem de células somáticas demonstra a instauração de um processo inflamatório na glândula mamária, sendo esta informação utilizada para o diagnóstico da mastite subclínica. Vários fatores podem influenciar no aumento de células somáticas no leite, dentre eles o estágio de lactação, o volume de produção, a raça e o número de lactações do animal, a estação do ano e o microrganismo envolvido no processo infeccioso (SHARMA et al., 2011).

Segundo Tangorra et al. (2010), as células somáticas fazem parte do mecanismo natural de defesa do animal e são representadas basicamente por leucócitos e células do epitélio secretor glandular. Os leucócitos são mobilizados da corrente sanguínea para o tecido mamário, mediante alterações na permeabilidade capilar. O aumento do número destas células no leite é um indicativo do estado imunológico da vaca frente alguma uma infecção. Podendo variar conforme o tipo de secreção, a composição das células somáticas no leite bovino é de $2 \%$ células do epitélio glandular, $3 \%$ células polimorfonucleares, $16 \%$ linfócitos e $80 \%$ macrófagos (SHARMA et al., 2011). O processo inflamatório subclínico da glândula mamária necessita de testes de campo como o California Mastitis Test (CMT) ou de laboratório como a contagem direta ou eletrônica de células somáticas para seu diagnóstico (PANTOJA et al., 2009).

Segundo Langoni (2017), os aspectos negativos da forma subclínica das mastites são amplamente conhecidos pela destruição do parênquima mamário, resultando em perda funcional do tecido secretor, bem como redução da qualidade do leite e de seus derivados. O que pesa de fato, no caso das mastites subclínicas são os prejuízos pela diminuição da produção ao nível de propriedade e do rendimento da produção na indústria de laticínios.

\section{- California Mastitis Test CMT}

Segundo Richter et al., (2013), a contagem de células somáticas pode ser realizada indiretamente, avaliando-se a viscosidade do leite após adição de um reagente próprio, ou diretamente, contando-se as células através do microscópio ou por meio de equipamentos eletrônicos.

O California Mastitis Test (CMT) é um método indireto, que avalia a quantidade de células somáticas do leite, sob a ação de um detergente aniônico que atua rompendo o citoplasma e núcleo das células, liberando o material genético no meio. A formação do gel ocorre pela interação dos ácidos nucléicos celulares com o detergente, quanto mais significativa a viscosidade, maior a quantidade de células somáticas no leite (BELOTI et al., 2015). É um método de triagem barato, de fácil execução e interpretação, capaz de detectar mastite subclínica podendo ser realizado no campo, como ilustra a figura 2 . 


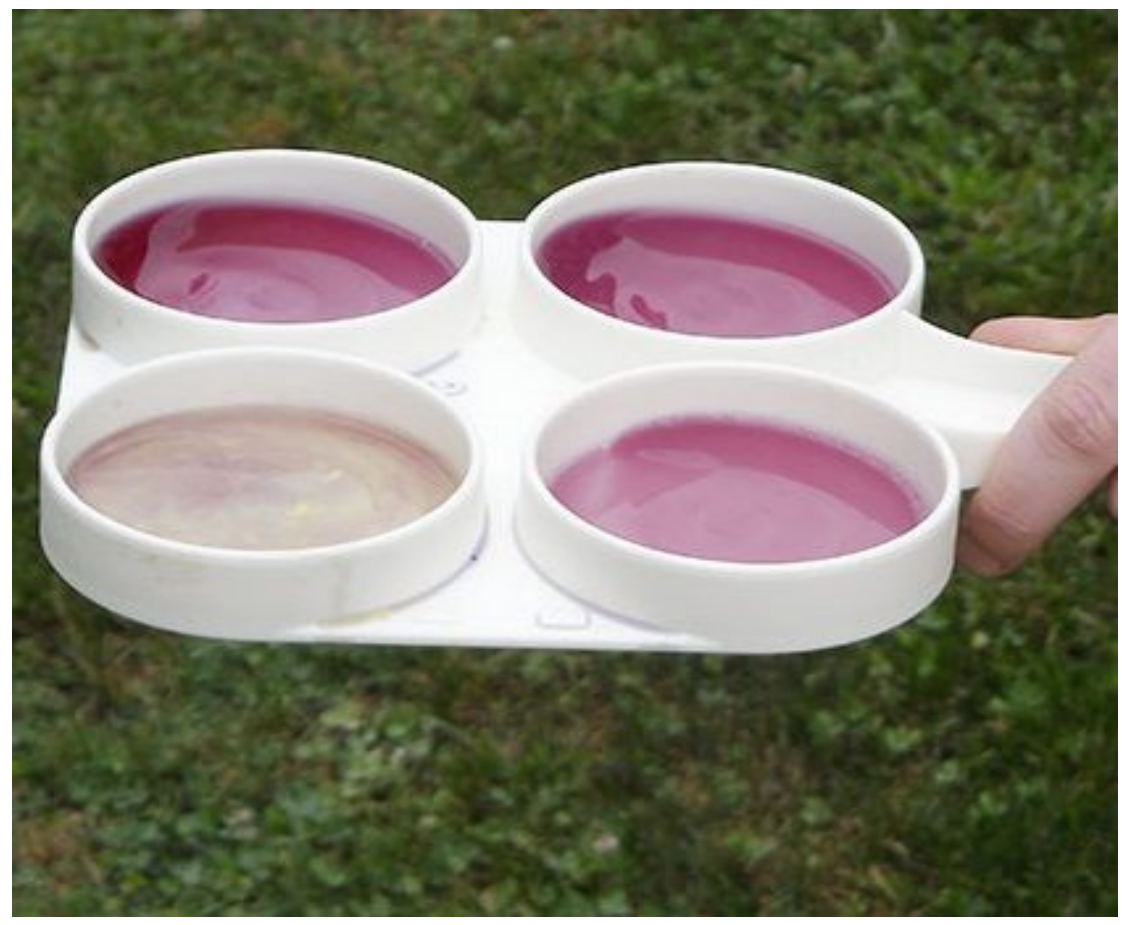

FIGURA 2 - Teste do CMT sendo realizado à campo. Fonte: RENNO et al., (2016).

De acordo com BELOTI et al. (2015), este teste é usualmente realizado após o teste da caneca do fundo escuro e do descarte dos primeiros jatos na ordenha, utilizando partes iguais de leite e reagente, sendo $2 \mathrm{~mL}$ o recomendado. A amostra em análise pode ser classificada de acordo com uma escala de 5 níveis, que corresponde a um valor aproximado de células somáticas a depender do grau de gelatinização visualizado durante o teste, como mostra o quadro 1 , a partir de uma pequena formação de gel, entende-se que há alteração na composição do leite do quarto mamário, caracterizando início de uma mastite subclínica.

QUADRO 1 - Interpretação do California Mastitis Test (CMT) e os valores aproximados de contagens de células somáticas correspondentes

\begin{tabular}{|l|l|l|}
\hline Classificação & Formação do gel & $\begin{array}{l}\text { Células somáticas por } \\
\mathrm{mL}\end{array}$ \\
\hline 0 & Ausência & 0 a 200.000 \\
\hline Traços & Pequena formação & 150.000 a 500.000 \\
\hline+ & Pequena a moderada & 400.000 a 1.500 .000 \\
\hline++ & Moderada & 800.000 a 5.000 .000 \\
\hline+++ & Consistente & $>5.000 .000$ \\
\hline
\end{tabular}

Fonte: Philpot, Nickerson, (2002) 
Santos e Fonseca (2007), recomendam a utilização do CMT para as seguintes situações: detecção de mastite subclínica em vacas recém-adquiridas no plantel; determinação de qual quarto mamário se encontra infectado, quando a vaca apresenta alta CCS na amostra composta de leite; detecção e controle mensal da mastite subclínica do rebanho; avaliação da mastite subclínica após o parto para identificação de infecções relacionadas com o período seco e avaliação do tratamento da vaca seca.

\section{- Wisconsin Mastitis Test WMT}

O Wisconsin Mastitis Test é um aprimoramento do CMT, realizado em tubo graduado com a finalidade de eliminar a subjetividade da interpretação dos resultados do California Mastitis Test (FONSECA; SANTOS, 2007).

Segundo Philpot e Nickerson (2002), esse teste utiliza o mesmo reagente do CMT diluído em água destilada na proporção de 1:1. Empregam-se $2 \mathrm{~mL}$ do reagente diluído misturado em $2 \mathrm{~mL}$ de amostra de leite em tubo perfurado, cujo orifício apresenta $1,15 \mathrm{~mm}$ de diâmetro. Por meio de movimentos rotacionados do tubo faz-se a homogeneização da mistura, e escoa-se o líquido por 15 segundos antes de retornar à posição original do tubo (BELOTI et al., 2015).O resultado do teste é expresso em milímetros, sendo correlacionado com o número de células somáticas, como demonstra o quadro 2.

QUADRO 2 - Relação entre CMT, WMT e CCS.

\begin{tabular}{lll}
\hline CMT & WMT $(\mathrm{mm})$ & CCS $(\mathrm{cel} / \mathrm{mL})$ \\
\hline 0 & 3 & 140.00 \\
& 4 & 165.000 \\
Traços & 5 & 195.000 \\
& 6 & 225.000 \\
& 7 & 260.000 \\
& 8 & 300.000 \\
& 9 & 340.000 \\
10 & 380.000 \\
& 11 & 420.000 \\
12 & 465.000 \\
13 & 515.000 \\
14 & 565.000 \\
15 & 620.000 \\
16 & 675.000 \\
17 & 730.000 \\
18 & 790.000 \\
19 & 855.000 \\
20 & 920.000 \\
21 & 990.000 \\
22 & 1.055 .000 \\
23 & 1.130 .000 \\
24 & 1.200 .000 \\
\hline
\end{tabular}




\begin{tabular}{lll}
\hline 25 & 1.280 .000 \\
26 & 1.360 .000 \\
27 & 1.440 .000 \\
28 & 1.525 .000 \\
29 & 1.610 .000 \\
30 & 1.700 .000 \\
31 & 1.800 .000 \\
32 & 1.920 .000 \\
33 & 2.030 .000 \\
& 34 & 2.180 .000 \\
\hline
\end{tabular}

Fonte: Adaptado de Philpot, Nickerson, (2002).

\section{- Contagem de Células Somáticas (CCS)}

A contagem precisa de células somáticas em leites individuais e de conjunto é a melhor ferramenta de monitoramento da sanidade do úbere do rebanho (BELOTI et al., 2015). De acordo com Santos e Fonseca (2007), a CCS é um bom indicador da probabilidade de ocorrência de uma infecção intramamária, quanto maior a contagem de células somáticas, maior é a probabilidade que a vaca esteja infectada. O leite de um quarto não infectado apresenta CCS menor que $100.000 \mathrm{cel} / \mathrm{mL}$, enquanto a CCS de um quarto infectado é geralmente superior a $200.000 \mathrm{cel} / \mathrm{mL}$, o que indica a ocorrência de mastite subclínica.

A contagem quantitativa de células somáticas pode ser realizada pelos métodos de contagem microscópica em lâminas ou por meio de equipamentos eletrônicos mais precisos através de diferentes técnicas de análises, sendo a mais usada a citometria de fluxo (RICHTER et al., 2013).

O método eletrônico de CCS apresenta uma série de vantagens em relação ao CMT e ao WMT. Em primeiro lugar, o procedimento eletrônico para CCS pode ser automatizado, possibilitando maior rapidez, precisão de resultados e análise de grande número de amostras. Outra vantagem é a possibilidade de conservar as amostras em temperatura ambiente e enviá-las pelo correio para um laboratório especializado; por último, a não influência da interpretação de quem faz o teste como ocorre no CMT e, dessa forma, os resultados podem ser comparados entre si (SANTOS; FONSECA, 2007). Porém, Melo et al. (2014) enfatizam que, devido ao alto custo destes equipamentos, a contagem manual das células somáticas por meio do microscópio ainda se faz necessária.

- Microscopia óptica

Segundo Jesus et al. (2014), a contagem realizada através da microscopia óptica é o método de referência para a determinação da CCS em leite cru, adotado pela Federação Internacional do Leite (FIL), e é utilizado para calibração de contadores eletrônicos mais modernos. Baseia-se na distribuição homogênea de uma amostra de $0,01 \mathrm{~mL}$ de leite em uma área de $1 \mathrm{~cm}$ delimitada na superfície de uma lâmina com o auxílio de uma pipeta automática calibrada. Após a secagem, as lâminas devem ser coradas com uma solução de azul de metileno 0,6\% e contadas por meio da observação em um microscópio óptico (MARSHALL, 1992).

De acordo com Reis e Lopes (2014), embora a análise pelo método de microscopia direta forneça informações essenciais sobre a condição da matériaprima, trata-se de um procedimento que requer um trabalho intenso, com ampla variabilidade de interpretação entre diferentes observadores. Métodos clássicos de análises, como é o caso dessa técnica, que, por muito tempo, foi 
referência na determinação do parâmetro exigido, são limitados por não terem sido concebidos para a análise em série de uma grande quantidade de amostras, sendo necessária mão-de-obra excessiva que, devido ao seu custo cada vez maior, impede a aplicação rentável (DIGIOVANI et al., 2017).

\section{- Microscopia eletrônica}

Diante das limitações que a microscopia direta impõe, a CCS pode ser realizada em equipamentos eletrônicos, Somacount $\AA^{\circledR}$ (Bentley Instruments Incorporated®) e Fossomatic® (Foss Eletric $\AA$, Hillerod, Dinamarca) (figura 3) são alguns exemplos. Esses equipamentos são utilizados pela Rede Brasileira de Laboratórios de Controle da Qualidade do Leite - RBQL como alternativa para aperfeiçoar o controle leiteiro e a qualidade do leite (REIS; LOPES, 2014).

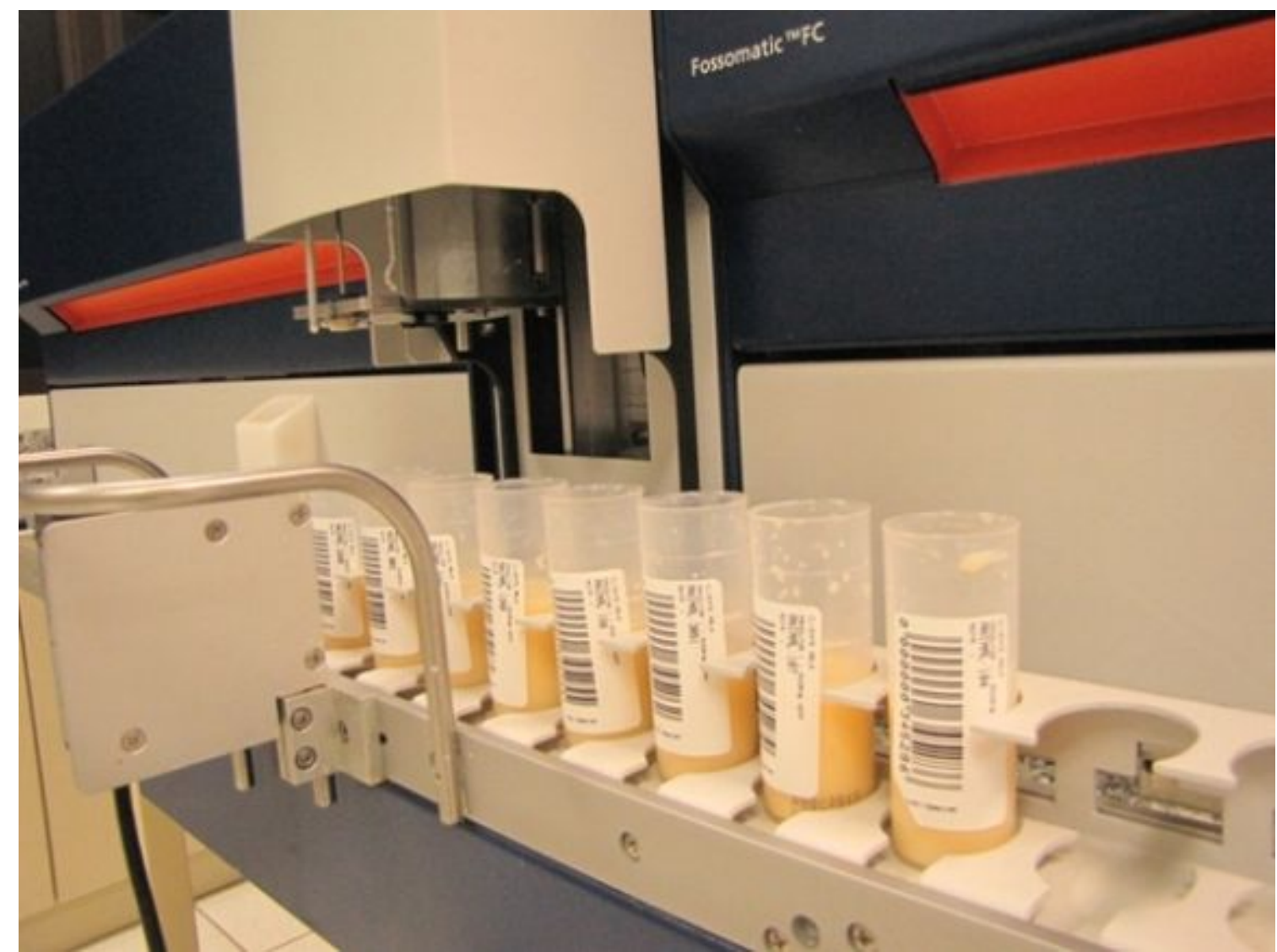

FIGURA 3 - Equipamento eletrônico Fossomatic para contagem de células somáticas através da citometria de fluxo. Fonte: CRUZ et al., (2018).

O princípio da citometria de fluxo consiste na medição de características celulares quando estas se encontram suspensas em meio fluido (BARRIENTOS et al., 2000). Segundo Reis e Lopes (2014), na análise, uma alíquota da amostra é coletada pelo instrumento, aquecida a $67^{\circ} \mathrm{C}$ e levada a uma seringa contendo o corante tampão brometo de etídio, com a finalidade de corar o DNA das células. Em seguida, 50 L da amostra são carreadas por um líquido para o interior do equipamento, ocorrendo a incidência de raio laser sobre a amostra. $\mathrm{O}$ brometo de etídio é um agente intercalante utilizado como marcador fluorescente, este penetra e intercala com DNA nuclear gerando um sinal fluorescente que é usado para estimar a CCS no leite (HOGEVEEN, 2010). 


\section{- Condutividade Elétrica}

Durante um processo inflamatório da glândula mamária, ocorre uma série de alterações tanto na composição como nas características físico-químicas do leite produzido, que são atribuídas a três fatores principais: alterações na permeabilidade vascular devido ao processo inflamatório; lesão do epitélio secretor responsável pela síntese de alguns componentes específicos do leite, ação de enzimas de origem das células somáticas e microrganismos presentes na glândula mamária (SANTOS; FONSECA, 2007).

Em um leite mastítico ocorre diminuição de aproximadamente $10 \%$ do teor de lactose comparado ao leite de uma vaca saudável. A lactose desempenha papel fundamental para o equilíbrio osmótico do leite em relação ao sangue, seu decréscimo leva a um mecanismo de compensação a fim de restabelecer esse equilíbrio osmótico, consistindo em um acréscimo da passagem de íons sódio e cloreto do sangue, que é possível devido ao aumento da permeabilidade dos vasos sanguíneos, para o leite, resultando em aumento da sua condutividade elétrica (ZAFALON et al., 2005; SANTOS; FONSECA, 2007; FERREIRA et al., 2015).

Segundo Neville e Jensen (1995), a condutividade elétrica é a propriedade que certas substâncias possuem de favorecerem, ou não, a passagem da corrente elétrica ou calorífera, variando de acordo com a natureza da substância. No leite, os íons são os principais componentes para se conduzir eletricidade, a corrente elétrica irá fluir mais facilmente por um leite com aumento nas concentrações dos íons sódio e cloreto, ou seja, em um leite com mastite, do que por um leite considerado saudável (ZAFALON et al., 2005).

A pesquisa do teor de cloretos e da condutividade elétrica do leite são métodos que podem ser utilizados como auxiliares no diagnóstico da mastite subclínica. O aumento da CE do leite é diretamente proporcional ao aumento da inflamação do úbere e da contagem de células somáticas (CCS) (FERRERO et al., 2014).

De acordo com Souza et al. (2017), a CE é obtida de maneira fácil, rápida e com baixo custo, se tornando uma importante ferramenta no controle da mastite, principalmente se comparado a informações de presença de células somáticas, onde se faz necessário o envio de amostras a um laboratório.

A condutividade elétrica do leite é mensurada em miliSiemens (mS). A CE do leite de vacas sadias, sem sintomas de mastite, pode variar entre 4 a $5 \mathrm{mS}$, sendo que estes valores aumentam para 5,37 em casos subclínicos e para 6,73 mS em casos clínicos de mastite, ainda que possa ocorrer variação entre os animais e em função do tipo de agente causador de mastite. (FERRERO et al., 2014). Como a mastite é um evento que ocorre no quarto do úbere, medições da CE a este nível podem dar a possibilidade de comparar os quartos do animal, aumentando assim a confiabilidade do teste (SOUZA et al., 2017).

Para mensuração da CE existem dois tipos de equipamentos, um aparelho portátil (figura 4) e um equipamento acoplado à ordenhadeira automatizada. Em sistemas de ordenha automatizados e computadorizados ocorre a detecção de alterações automaticamente durante as atividades de ordenha, por meio de softwares, emitindo um sinal de alerta, indicando o animal que pode estar com mastite (LOPES, 2014; BELOTI et al., 2015). 


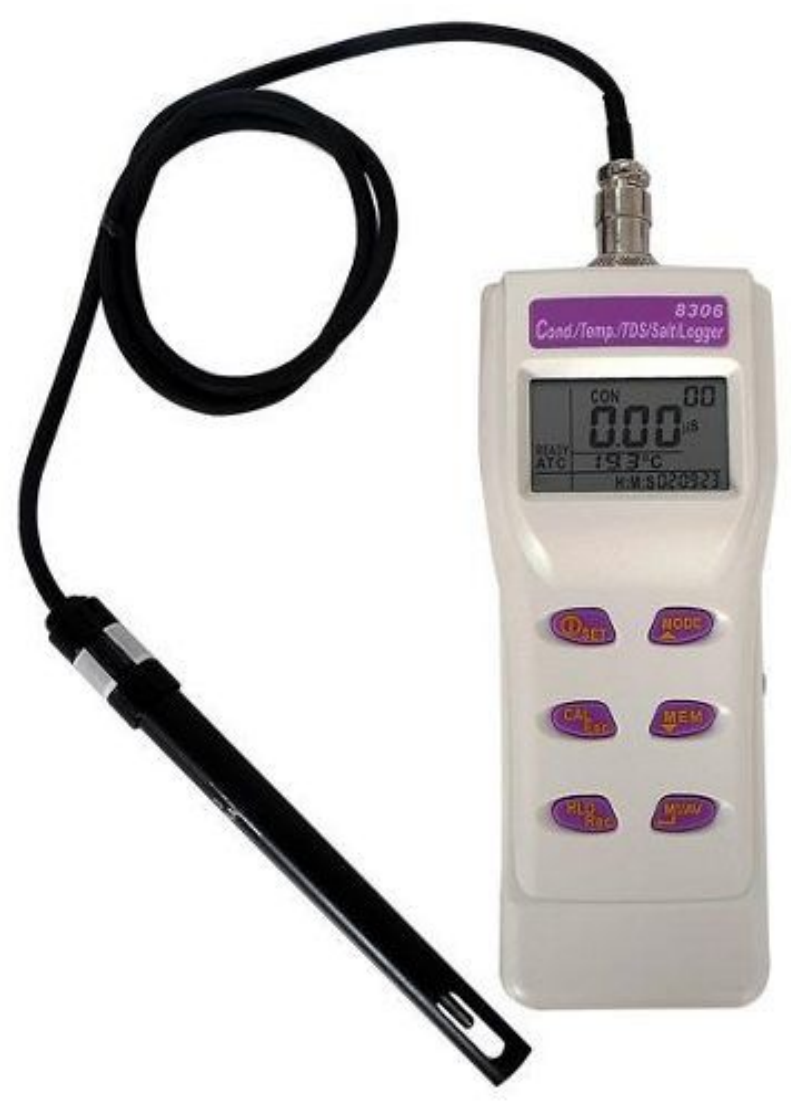

FIGURA 4 - Modelo de aparelho portátil para medição da CE do leite.

Segundo Reis e Lopes (2014), o equipamento portátil tem a vantagem de poder ser utilizado em vários locais e ser de fácil utilização, entretanto, possui protocolos a serem seguidos, nos quais a coleta de amostras homogeneizadas a partir da ordenha completa, calibragem do aparelho com solução padrão antes do início dos testes, e mensurações devem ser realizadas em temperatura ambiente.

\section{- Análise microbiológica do leite}

$O$ isolamento microbiológico de microrganismo patogênico em amostra de leite é considerado o método diagnóstico padrão para a mastite. Além disso, a identificação do agente causador da mastite é útil para recomendações de tratamento e descarte, e principalmente para a adoção e monitoramento de medidas de controle. A identificação da espécie é feita por meio de cultura microbiológica em laboratório especializado (SANTOS; FONSECA, 2007).

Uma vez detectada nos animais, a eliminação efetiva do agente causador de mastite depende diretamente de sua identificação adequada e verificação de sua sensibilidade a diferentes antimicrobianos. Para tanto, amostras de leite devem ser coletadas em tubos esterilizados de maneira asséptica dos animais identificados com altas contagens de células somáticas, e semeadas em meios de cultura, seletivos e não seletivos, para isolamento dos agentes infecciosos. Após isolamento de culturas, as mesmas devem ser caracterizadas por testes laboratoriais simples para identificação de gênero e espécie, sempre que possível, e verificação de sua sensibilidade a diferentes antimicrobianos, pela realização de um antibiograma. A identificação correta de qual antimicrobiano tem efeito contra o agente isolado é fundamental para o sucesso da terapia (BELOTI et al., 2015). 


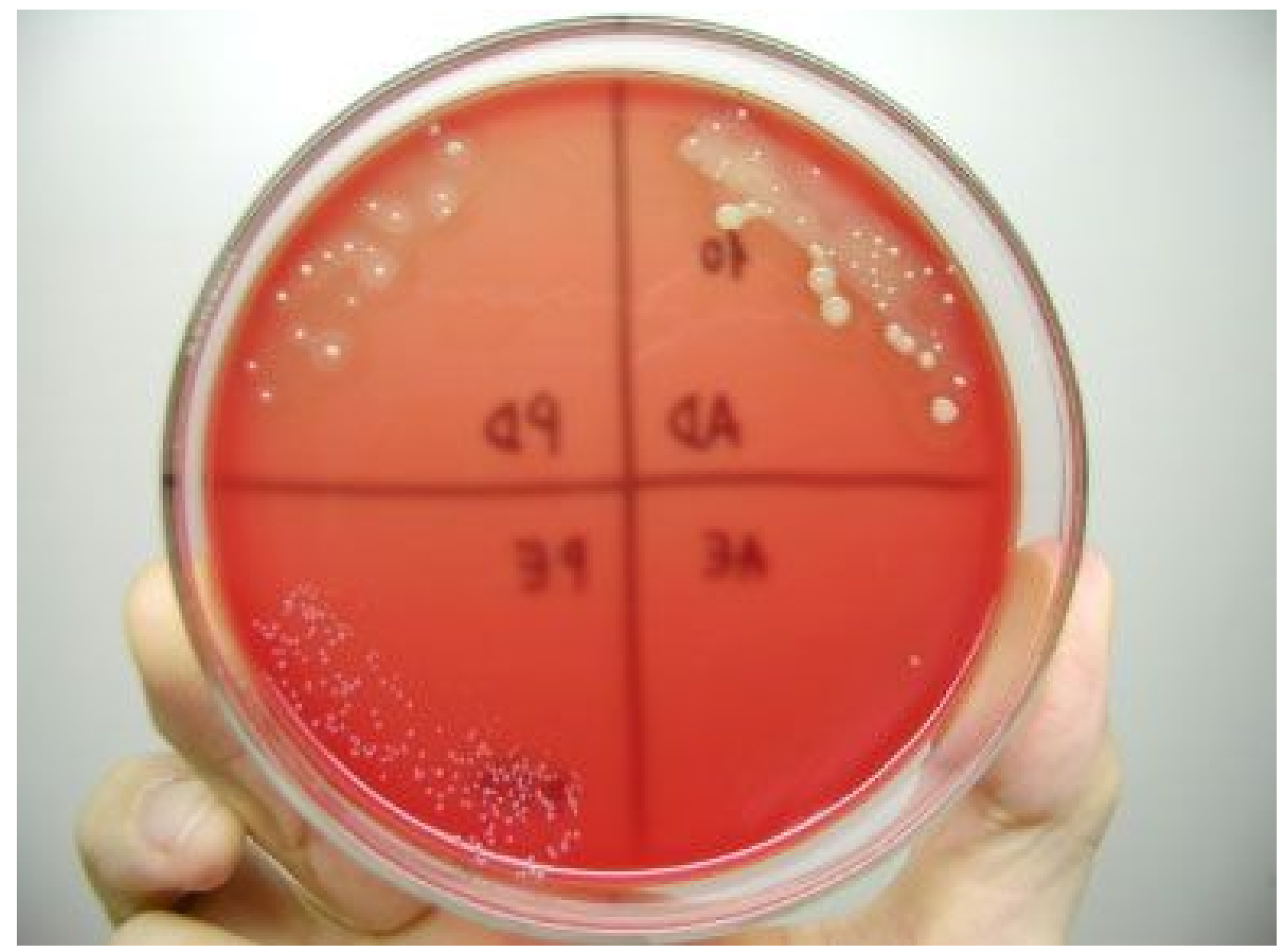

FIGURA 4 - Cultura de amostra de leite dos quatro quartos mamários individuais. Fonte: SANTOS; FONSECA, (2007).

\section{CONSIDERAÇÕES FINAIS}

Segundo Teixeira e Tomich (2018), com o objetivo de aumentar ou melhorar a detecção de casos de mastite, produtores de leite têm investido em sistemas automatizados de coleta de dados como por exemplo o uso da mensuração da condutividade elétrica do leite, aparelhos eletrônicos para CCS e até mesmo uso de sensores computadorizados acoplados à ordenhadeira, que utilizam conjuntamente esses dados para auxiliar no diagnóstico de mastite (SORENSEN et al., 2016).

Por ser uma das enfermidades mais presentes e onerosas no gado leiteiro, variados métodos de detecção de mastites clínicas e subclínicas devem ser empregados para diagnóstico precoce de patologias relacionadas à pecuária de leite. Para isso, é importante que os meios de diagnósticos, expostos nessa revisão de literatura, sejam utilizados de forma integrada em programas de controle de mastites, em benefício da saúde, produtividade e bem-estar dos animais.

\section{REFERÊNCIAS}

ACOSTA, A. C.; SILVA, L. B. G.; MEDEIROS, E. S.; PINHEIRO-JUNIOR, J. W.; MOTA, R. A. Mastites em ruminantes no Brasil. Pesquisa Veterinária Brasileira, v. 36, n. 7, p. 565-573, 2016. Disponível em: http://dx.doi.org/10.1590/S0100736X2016000700001. 
ARCANJO, A. H. M.; OLIVEIRA, P. C. S.; MOREIRA, L. C.; JAYME, C. G.; SOARES, $\mathrm{N}$. A. et al Programa dos seis pontos de controle da mastite em rebanhos leiteiros Global Science and Technology, Rio Verde, v.10, n.01, p.78 - 88, jan/abr., 2017. Disponível em: https://rv.ifgoiano.edu.br/periodicos/index.php/gst/article/view/860

BARKEMA, H.W.; SCHUKKEN Y.H.; ZADOKS R.N. Invited review: The role of cow, pathogen, and treatment regimen in the therapeutic success of bovine Staphylococcus aureus mastitis. Journal of Dairy Science. 89 (6):1877-1895, 2006. Disponível em: https://doi.org/10.3168/jds.S0022-0302(06)72256-1

BARRIENTOS, A.A.; ARROYO, J.; CANTÓN, R.; NOMBELA, C.; SANCHEZ-PÉREZ, M. Applications of flow cytometry to clinical microbiology. Clinical Microbiology Reviews, v.13, p.167-195, 2000. DOI: 10.1128/cmr.13.2.167-195.2000

BELOTI, V.; TAMANINI, R.; NERO, L. A. Leite: obtenção, inspeção e qualidade. Londrina: Editora Planta, 2015.

BRITO, M. A. V. P.; BRITO, J. R. F.; RIBEIRO, M. T.; VEIGA, V. M. O. Padrão de infecção intramamária em rebanhos leiteiros: exame de todos os quartos mamários de vacas em lactação. Arquivo Brasileiro de Medicina Veterinária e Zootecnia, v. 51 , p. 129-135, 1999. ISSN 0102-0935. Disponível em: http://dx.doi.org/10.1590/S0102-09351999000200001.

CALLEFE, J. L. R.; LANGONI, H. Qualidade do leite: uma meta a ser atingida. Veterinária e Zootecnia, v. 22, n. 2, jun. 2015. p. 151-162.

CHAPAVAL L.; PIEKARSKI, P. R. B. Leite De Qualidade: manejo reprodutivo, nutricional e sanitário. Editora Aprenda Fácil. Viçosa - MG, 2016.

COSTA, E. O. Programa Nacional de Melhoria da Qualidade do Leite (PNMQL). Rev. Napgama, São Paulo. 8(2):18-21., 2005.

CRUZ, A. G.; ZACARCHENCO, P. B.; OLIVEIRA, C. A. F.; CORASSIN, C. H. Microbiologia, higiene e controle de qualidade no processamento de leites e derivados. Elsevier Brasil, 2018.

DIGIOVANI, D. B.; BORGES, M. H. F.; GALDIOLI, V. H. G.; MATIAS, B. F.; BERNARDO, G. M. et al Infrared thermography as diagnostic tool for bovine subclinical mastitis detection. Revista Brasileira de Higiene e Sanidade Animal, v. 10, n. 4, p. 685-692, 2017. Disponível em: http://dx.doi.org/10.5935/19812965.20160055

FERREIRA, G. A.; GUIRRO, E. C. B. P.; BLAGITZ, M. G.; LIBERA, A. M. M. P. D. et al. Estratégias de prevenção da mastite bovina no período de transição. Veterinária em Foco, v. 12, p. 80-91, 2015.

FERRERO, F. J.; VALLEDOR, M.; CAMPO, J. C. Screening method for early detection of mastitis in cows. Measurement, Oviedo, v. 47, n. 1, p. 855-860, 2014. Disponível em: https://doi.org/10.1016/j.measurement.2013.10.015 
FITZPATRICK, C. E.; CHAPINAL, N.; PETERSON-WOLFE, C. S.; DEVRIES, T. J.; KELTON, D. F. et al. The effect of meloxicam on pain sensitivity, rumination time, and clinical signs in dairy cows with endotoxin-induced clinical mastitis. Journal of Dairy Science, v. 96, p. 2847-2856, 2013. Disponível em: https://doi.org/10.3168/jds.2012-5855

GARGIULO, J. L.; EASTWOOD, C. R.; GARCIA, S. C.; LYONS, N. A. Dairy farmers with larger herd sizes adopt more precision dairy technologies. Journal of Dairy Science, v. 101, p. 1-8, 2018. Disponível em: https://doi.org/10.3168/jds.2017-13324

HOGEVEEN, H.; KAMPHUIS, C.; STEENEVELD, W.; MOLLENHORST, H. Sensors and Clinical Mastitis - The Quest for the Perfect Alert. Sensors, Wageningen, v. 10, n. 2, p. 7991-8009, 2010. Disponível em: https://doi.org/10.3390/s100907991

LANGONI, Helio et al. Considerações sobre o tratamento das mastites1. Pesquisa Veterinaria Brasileira, v. 37, n. 11, p. 1261-1269, 2017. Disponível em: http://dx.doi.org/10.1590/s0100-736x2017001100011

LANGONI, H. Qualidade do leite: utopia sem um programa sério de monitoramento da ocorrência de mastite bovina. Pesquisa Veterinaria Brasileira 2013, vol.33, n.5, pp.620-626. Disponível em: http://dx.doi.org/10.1590/S0100-736X2013000500012.

LANGONI, H.; GUIMARÃES, F. F.; SALINA, A.; RIBEIRO, M. G.; BAIO, P. V. P. et al. Molecular characterization of Corynebacterium bovis causing clinical mastitis and increasing somatic-cell count. International Journal of Advanced Veterinary Science Technology. 5:248-255, 2016. Disponível em: http://scientific.cloudjournals.com/index.php/IJAVST/article/view/Sci-438

LEÃO, J. M.; LIMA, J. A. M.; PÔSSAS, F. P.; PEREIRA, L. G. R. Uso da termografia infravermelha na pecuária de precisão. Embrapa Gado de Corte, p. 97-109, 2015.

LOPES, B. C.; MANZI, M. P.; LANGONI, H. Etiologia das mastites: pesquisa de micro-organismos da classe Mollicutes. Veterinária e Zootecnia. jun.; 25(2):, 2018. Disponível em: https://rvz.emnuvens.com.br/rvz/article/view/41

MARSHALL, R. T. Standard methods for the examination of dairy products. Baltimore. American Public Health Association. 546 p., 1992.

MELO, G. J. A., et al. Method thresholding automatic for somatic cell count in microscopic images. Revista Geintec: gestão, inovacão e tecnologias, v. 4, p. 1283-1291, 2014.

MELO, G. J. A.; GOMES, V.; ALMEIDA, L. A. L.; LIMA, A. C. C.; BACCILI, C. C. Método para contagem de células somáticas do leite bovino para imagens capturadas do microscópio óptico. Zootecnia Trop. v. 32, n. 1, p. 77-82, 2014. Disponível em: http://www.scielo.org.ve/pdf/zt/v32n1/art08.pdf

NEVILLE, M. C.; JENSEN, R. G. The physical properties of human and bovine milks. San Diego: Academic Press, 1995. 85 p. 
NETO, F P; ZAPPA, V. Mastite Em Vacas Leiteiras- Revisão De Literatura. Revista Científica Eletrônica De Medicina Veterinária, v. 16, p. 1679-7353, 2011.

PAES, A. D. S; FERREIRA, A. S.; SOARES-FERREIRA, P. R. O. Mastite Bovina . Revista Conexão Eletrônica, v. 14, p. 736-746,2017.

PANTOJA, J. C. F.; REINEMANN, D. J; RUEGG, P. L. Associations among milk quality indicators in raw bulk milk. Journal of Dairy Science. 92(10):4978-4987. Pinzón-Sánchez C., 2010. Disponível em: https://doi.org/10.3168/jds.2009-2329

PHILPOT, W. N.; NICKERSON, S. C. Vencendo a luta contra a mastite. São Paulo: Editora Milkbizz; 2002. 30p.

RENNO, F. P.; PEREIRA, J. C.; COSTA, M. G. Manejo Das Ordenhas Manual e Mecanica e Qualidade do leite, LK EDITORA, 2016.

RICHTER, E. M.; MELO, T.; ZEOLLA, N.; GROENWOLD, V. Ações de manejo e sanitárias no controle de CCS em rebanhos leiteiros agroecológicos. Cadernos de Agroecologia 8(2), 2013. Disponível em: http://revistas.abaagroecologia.org.br/index.php/cad/article/view/13697

SANTOS, M. V.; FONSECA, L. F.L. Estratégias de controle de mastite e melhoria da qualidade do leite. Barueri: Manole, Pirassununga: Ed Dos Autores; 2007.

STANGAFERRO, M. L.; WIJMA, R.; CAIXETA, L. S.; AL-ABRI, M. A.; GIORDANO, J. A. Use of rumination and activity monitoring for the identification of dairy cows with health disorders: Part I. Metabolic and digestive disorders. Journal of Dairy Science, v. 99, p. 7395-7410, 2016. Disponível em: https://doi.org/10.3168/jds.201610907

TANGORRA, F. M.; ZANINELLI, M.; COSTA, A.; AGAZZI, A.; SAVOINI, G. Milk electrical conductivity and mastitis status in dairy goats: Results from a pilot study. Small ruminant research, 90(1): 109-113, 2010. Disponível em: https://doi.org/10.1016/j.smallrumres.2010.02.006

ZAFALON, L. F.; FILHO, A. N.; OLIVEIRA, J. V.; RESENDE, F. D. Comportamento da condutividade elétrica e do conteúdo de cloretos do leite como métodos auxiliares de diagnóstico na mamite subclínica bovina. Pesquisa Veterinária Brasileira, Nova Odessa, v. 25, n. 3, p. 159-163, 2005. Disponível em: http://www.scielo.br/pdf/pvb/v25n3/a06v25n3.pdf 